\title{
O enfermeiro como facilitador do processo de aleitamento materno
}

A Organização Mundial da Saúde (OMS) em conjunto com o Ministério da Saúde (MS) recomenda a amamentação por dois anos ou mais com exclusividade nos primeiros seis meses de vida da criança. Os benefícios da amamentação são reconhecidos mundialmente $\mathrm{e}$ cientificamente para a dupla, mãe e recém-nascido $(R N)$, para a criança é um fator determinante no desenvolvimento imunológico, redução de processos alérgicos, prevenção da obesidade, hipertensão, colesterol, diabetes e redução da morbimortalidade infantil devido a infecções respiratórias e diarreia, favorecendo o desenvolvimento cognitivo e da cavidade bucal, no entanto para a mulher que amamenta, estas obtém proteção contra o câncer de mama, câncer de ovário, câncer uterino, hipercolesterolemia, hipertensão, cardiopatias, obesidade; doenças metabólicas, osteoporose, depressão pós-parto, como também melhor benefício custo financeiro e duplicação afetiva. Quanto aos dados nacionais, apenas $96 \%$ das mulheres iniciam a amamentação, sendo que somente $11 \%$ amamentam com exclusividade até 4 a 6 meses, $41 \%$ conduzem o aleitamento materno até 1 ano, e $14 \%$ até no máximo de 2 a 3 anos, concre- tizando uma taxa abaixo do recomendando pela OMS e MS. Portanto iniciar alimentos suplementares antes dos seis meses de vida pode prejudicar a saúde da criança, favorecendo o aumento de episódios de diarreia, internações por doenças respiratórias e desnutrição por déficit na absorção de nutrientes importantes como ferro e zinco. Vale ressaltar que um dos motivos para o desmame precoce de crianças menores de 6 meses está relacionado diretamente a questões psicossociais, como ausência de confiança, indecisões, crenças, dor nos mamilos e ansiedade. Ocasionando experiências frustrantes e negativas para a continuidade do aleitamento materno exclusivo (AME). Isso remete o quanto é importante e necessário a busca de novas estratégias, objetivando o reestabelecimento do AME, como também a promoção, segurança, proteção e apoio às nutrizes. As estratégias e tecnologias como álbum seriado, cartilha, vídeo educativo, manual, oficinas, oferecem apoio, suporte e orientações necessárias para a eficácia do aleitamento materno. Outro ponto que apresenta relevância para a obtenção de bons resultados está relacionado ao aconselhamento em amamentar. Diante destas necessidades o profissional enfermeiro vem se destacando em sua prática clínica como facilitador e multiplicador para o alcance do sucesso em amamentar.

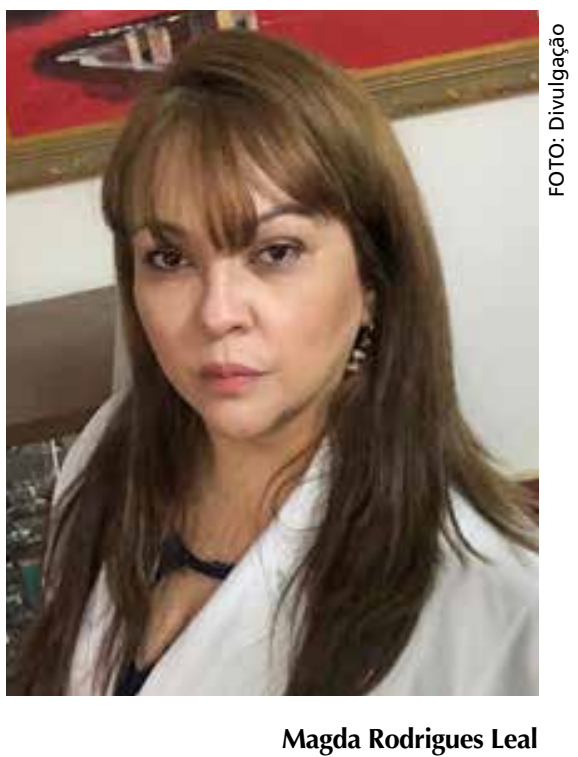

Pós Graduação em Enfermagem Obstétrica, Especialização em Saúde Coletiva com Ênfase em Saúde da Família. Profa. Curso de Enfermagem da Universidade Nove de Julho- Uni9- São Paulo-SP. Mestranda em Ciências da Saúde pelo programa de Pós-Graduação em Ciências da Saúde - Strictu Sensu, do Instituto de Assistência Médica ao Servidor Público Estadual de São Paulo.

\section{Referências}

1. Ministério da Saúde (BR), Secretaria de Atenção à Saúde. Aleitamento Materno e Alimentação Complementar. $2^{\text {a }}$ edição. Cadernos de Atenção Básica, no 23. Brasília (DF); 2015.

2. Quitete JB. A amamentação sob a égide de redes de apoio: uma estratégia facilitadora. 2020;24(1):1-8

3. Andreazzi Duarte D. BENEFÍCIOS DA AMAMENTAÇÃO. REAEnf [Internet]. 16jul.2019 [citado 7jul.2020];1:001. Available from: https://acervomais.com.br/index.php/enfermagem/article/view/1272

4. Javorski M, Rodrigues AJ, Cláudia R, Dodt M, Almeida PC De, Pedrosa L. amamentar e na prática do aleitamento materno exclusivo * . 2018;1-8. 5. Almeida JM De, Araújo S De, Luz B. REVISTA PAULISTA Apoio ao aleitamento materno pelos profissionais de saúde: revisão integrativa da literatura. Rev Paul Pediatr [Internet]. 2015;33(3):355-62. Available at: http:// dx.doi.org/10.1016/j.rpped.2014.10.002

6. Dodou HD, Fayma A, Chaves L, Ximenes LB, Teixeira C, Vasconcelos M. promoção do aleitamento materno: revisão sistemática da literatura. 2018;1-12. 